\title{
PATHWAYS UTILIZED FOR ANTENATAL HEALTH SEEKING AMONG WOMEN IN THE GA EAST DISTRICT, GHANA
}

\author{
R.N.O. ARYEETEY ${ }^{1}$, M. AIKINS ${ }^{2}$, P. DAKO-GYEKE ${ }^{2}$ and P.B. ADONGO ${ }^{2}$ \\ ${ }^{1}$ Department of Population, Family and Reproductive Health, University of Ghana School of Public Health, \\ P. O. Box LG 13 Legon, Accra, Ghana, ${ }^{2}$ School of Public Health, University of Ghana, Legon, Accra, Ghana
}

DOI: $h t t p: / / d x$. doi.org/10.4314/gmj.v49i1.8

Corresponding Author: Dr. Richard Nii Okai Aryeetey

Email: raryeetey@ug.edu.gh

Conflict of Interest: None declared

\section{SUMMARY}

Background: Ghana's maternal mortality ratio has been declining over the last two decades but at a rather slow pace. Poor access to effective maternity care is identified as one of the key challenges of maternity care. The current study mapped out the pathways to pregnancy care seeking among urban-dwelling adult women in a peri-urban district located in the Greater Accra region of Ghana.

Methods: A total of 300 women who had a live birth in the last 12 months participated in a communitybased survey. They answered questions on care seeking behavior related to their last pregnancy. A multivariate Logistic regression model was used to identify factors associated with multiple care seeking behavior.

Results: Almost all women in the survey (98\%) reported accessing skilled antenatal care (ANC) from a biomedical provider, although $35 \%$ begun ANC later than the first trimester. About $45 \%$ of women simultaneously utilized both ANC and alternative care providers (ACP) including traditional birth attendants, herbalists, and spiritualists. A complex pathway to antenatal care seeking behavior involving shuttling between providers was observed. Controlling for household wealth, household size, and age, seeking care from multiple providers concurrently was associated with residence in Kwabenya sub-district $\mathrm{OR}=2.13(95 \% \mathrm{CI}: 1.28$, $3.55)$ and previous abortion $\mathrm{OR}=2.08$ (95\% CI: 1.11 , 3.91)

Conclusions: Urban-dwelling women in Ga East District seek antenatal care concurrently from multiple sources. Health system interventions must seek ways to integrate alternative care providers into the existing biomedical health care system.

Keywords: Keywords: multiple care seeking, pregnancy, pathway, alternative care, antenatal

\section{INTRODUCTION}

Ghana's maternal mortality ratio is estimated to have declined by $40 \%$ between 1990 and $2010^{1}$, albeit, at a rather slow rate. ${ }^{2}$ Nevertheless, the country remains classified among the 40 countries with the highest maternal mortality ratios, globally. In the year 2008, 451 maternal deaths were recorded for every 100,000 live births in Ghana; this represented a decline from 740 in $1990 .^{3}$ Institutional data shows a similar trend of slow decline in all administrative regions, except in Greater Accra where the maternal mortality ratio has gone in the reverse direction ${ }^{3}$. Based on this evidence, it is unlikely that Ghana will be able to meet the Millennium Development goal of reducing maternal mortality.

Identifying the context-specific determinants of maternal mortality is urgently needed as a basis for intervention. The important direct medical causes of maternal deaths in low income settings are known and include hemorrhage, hypertensive diseases, and a high burden of infectious morbidity. ${ }^{4}$ Underlying these causes, however, are delays spanning the community and the health system prior to, and during labor. ${ }^{5}$ Current evidence shows that a majority $(96 \%)$ of pregnant Ghanaian women receive antenatal care (ANC) from a skilled provider. $^{6}$

This overall estimate, however, hides the fact that close to a quarter of pregnant women do not utilize ANC services for the recommended minimum of four times during each pregnancy. Additionally, almost half of pregnant women do not access antenatal care during the critical first trimester. Subsequently, during delivery, only about one half of women utilize skilled support in adequately resourced facilities. ${ }^{2}$ The question then is: if women are not utilizing proven biomedical maternity care, where are they getting care from during pregnancy and delivery? 
Earlier studies have reported in developing countries such as Ghana, that the gap in maternity and delivery care may be partly filled by alternative care providers. $^{7,8}$

Some of these studies have also demonstrated that women engage in multi-shopping for care from multiple care providers during a particular pregnancy. ${ }^{9,10}$ In Ghana, training of traditional birth attendants (TBA) used to constitute an important aspect of maternity care; only a few years ago, TBAs were providing a majority of obstetric support for women in places where access to trained midwives and other medical providers were limited. ${ }^{11}$ Currently, the role of TBAs is officially limited to providing non-delivery-related support during pregnancy, rather than deliveries. Although TBA training is no longer supported as a strategy for deliveries, according to the Ghana Maternal Health Survey of 2007, 29\% of deliveries were supervised by TBAs including $9 \%$ who were untrained. However, little information exists regarding the type of support and remedies they provide to women during pregnancy. This is especially important if women patronize TBAs due to access challenges or other reasons.

In 2011, The Ghana Health Service published the Millennium Development Goal Acceleration Framework and Country Action Plan for Maternal Health in Ghana. In this document, it was reported that the Greater Accra region is the only region in Ghana where maternal mortality ratio has worsened, since 1992. To understand the basis for unexpected outcome, it is important to know the care seeking behavior of women in this region.

Even more important is the need to unravel the pathways navigated by women as they go about seeking care during pregnancy. Based on earlier studies, it was anticipated that women will seek care from multiple sources for the same pregnancy. In addition, there is currently limited evidence on the factors associated with care seeking during pregnancy, in this urban setting. The current study therefore fills this knowledge gap.

\section{METHODS}

The study was carried out between November 2011 and May 2012 in the Ga East district of Ghana. The Ga East District is a mix of urban, peri-urban, and rural communities with about two-thirds of the district being peri-urban or urban. In 2012, the district's population was estimated at 276,017. The Taifa-Kwabenya and Madina sub-districts were purposively selected as sites for the data collection.
Taifa-Kwabenya was selected because its communities were mainly emerging developments with limited access to publicly managed health facilities that provide pregnancy and delivery care.

Residents in this area are known to seek care from other parts of Accra, including Central Accra, Pokuase, Nsawam, and Amasaman in the adjoining districts. ${ }^{12}$ On the other hand, the Madina sub-district is more urbanized with better access to social services including health care and public transportation. Most of the publicly managed health facilities in the Ga East district are located in the Madina Sub-district and are managed by the District Health Administration. A crosssectional study design involving a community survey, focus group interviews, and key informant interviews were implemented between November 2011 and September 2012. The survey was administered to 300 adult women who had delivered a live birth within the last 12 months. The communities included in the survey were drawn randomly from a list of all communities provided by the Municipal Health Administration.

Maps of the communities were obtained from the submunicipal public health offices and used to randomly select clusters in each sub-district for inclusion in the survey. In the Taifa-Kwabenya sub-district, 180 women were selected by systematic sampling in the clusters identified for participation in the survey. An additional 120 women were selected, similarly, from the Madina sub-district clusters. The total sample size of 300 women was determined to be adequate to estimate the proportion of women reporting at least four visits of antenatal services within a confidence interval of $95 \%$ and a precision of $5 \%{ }^{6}$.

More respondents were selected from Madina because it is more densely populated per cluster than in Taifa/Kwabenya. Each respondent endorsed an informed consent document by appending their signature or thumb printing, after they had read the document or it had been read and explained to them by the interviewer in English or other language they understood. To be included in the survey, women should be at least 18 years, lived in the selected community for at least 6 months prior to the survey, and had delivered a live born child within the last 12 months. Trained field staff administered the questionnaires to the women in faceto-face interviews.

The survey included three main tools: 1) a household roster describing household and demographic characteristics, 2) a care-seeking tool describing women care seeking behavior, places where care was sought from, barriers and access to care services, and 3) a Standard Patient Cost Questionnaire which documented wom- 
en's pathways to care seeking as well as the costs of seeking health care during pregnancy and delivery. The current study formed part of a larger study that also includes qualitative components focusing on beliefs and perceptions about pregnancy and care seeking. Ethical approval (certificate number 045/11-12) was obtained from the Noguchi Memorial Institute for Medical Research Institutional Review Board.

\section{Data processing and analysis}

Data was checked, coded and then captured electronically, using EpiData 3.1 (EpiData Assoc. Denmark). Analysis was completed using SPSS version 16 (SPSS Inc, Chicago). Data on characteristics of women and their household were summarized using frequencies and mean (standard deviation), as appropriate. Additionally, care seeking behavior and the pathways to accessing care were also summarized using frequencies. A multivariate logistic regression model was used to identify factors associated with simultaneous antenatal care seeking from multiple providers. Hypothesis testing was two-sided and an $\alpha$-level $<0.05$ was considered a statistically significant result.

\section{RESULTS}

\section{Study participant characteristics}

Three hundred women completed the survey in the Ga East district. Table 1 displays the detailed characteristics of the survey respondents.

Table 1 Background characteristics of study respondents

\begin{tabular}{|l|l|l|}
\hline Characteristics & N & $\mathbf{\%}$ \\
\hline Age groups, yr & & \\
\hline$<20$ & 7 & 2.3 \\
\hline $20-29$ & 157 & 52.4 \\
\hline $30-39$ & 127 & 42.3 \\
\hline $40-49$ & 9 & 3.0 \\
\hline Education completed & & \\
\hline None & 29 & 9.7 \\
\hline Primary & 33 & 11.0 \\
\hline JHS/middle & 145 & 48.3 \\
\hline Secondary & 63 & 21.0 \\
\hline Post-secondary & 30 & 10.0 \\
\hline Current occupation & & \\
\hline Unemployed & 51 & 17.0 \\
\hline Trading & 131 & 43.6 \\
\hline Artisan & 86 & 28.7 \\
\hline Other & 32 & 10.7 \\
\hline Current marital status & & \\
\hline Single & 17 & 5.7 \\
\hline Married & 191 & 63.6 \\
\hline Cohabiting & 92 & 30.7 \\
\hline Obstetric history & & $3.0^{*}$ \\
\hline Number of Pregnancies & $1.7^{\#}$ & $2 .{ }^{*}$ \\
\hline Number of children born alive & $1.3^{\#}$ & 19.8 \\
\hline Ever aborted & 59 & 4.7 \\
\hline Ever had stillbirth & 14 & \\
\hline${ }^{*}$ Mean, ${ }^{*}$ standard deviation & & \\
\hline & & \\
\hline & & \\
\hline & & \\
\hline & & \\
\hline & & \\
\hline & & \\
\hline & & \\
\hline
\end{tabular}

Most of the women (95\%) were between ages 20 and 39 years and had a mean age of $29.1+5.4$. Majority (79.3\%) had completed at least Junior High School and some were engaged in trading (43.6\%) and artisanal occupations (28.7\%), including mainly hairdressing and dressmaking.

Majority of the women (94.3\%) were either married or living with a partner in a cohabiting relationship. Most identified themselves as Christians (82.5\%). About $20 \%$ of the women were first time mothers. Also, about $20 \%$ of the women had either aborted a child or miscarried a previous pregnancy. Less than $5 \%$ of women reported ever having a stillbirth experience.

\section{Pregnancy experiences and care seeking}

About $90 \%$ of women reported receiving information on pregnancy-related complications from a health care worker (nurse or doctor) during their last pregnancy. Most women (78\%) reported at least one pregnancyrelated complication and about half $(53 \%)$ reported a minimum of two serious pregnancy-related complications (Table 2). The complications reported included swollen feet $(39.0 \%)$, abdominal pain $(47.7 \%)$, vaginal bleeding $(7.0 \%)$, losing consciousness $(3.3 \%)$ and convulsions $(1.0 \%)$.

Table 2 Complications of pregnancy and care seeking behavior of pregnant women in the Ga East district

\begin{tabular}{|c|c|c|}
\hline $\begin{array}{l}\text { Antenatal complications and care-seeking } \\
\text { behavior }\end{array}$ & $\mathbf{N}$ & $\%$ \\
\hline Reported 2 or more serious complications ${ }^{\#}$ & 159 & $53 \%$ \\
\hline Did not seek care for serious complications & 26 & 16.7 \\
\hline $\begin{array}{l}\text { Used home remedies for serious complica- } \\
\text { tions }\end{array}$ & 32 & 20.5 \\
\hline \multicolumn{3}{|l|}{ ANC care provided by } \\
\hline Medical doctor & 70 & 23.3 \\
\hline Nurse/midwife & 224 & 74.9 \\
\hline \multicolumn{3}{|l|}{ Type of facility where ANC was accessed } \\
\hline Public hospital/health center & 162 & 54 \\
\hline Private hospital/health center & 69 & 23 \\
\hline Mission hospital/health center & 37 & 12.3 \\
\hline Multiple facilities & 26 & 8.6 \\
\hline \multicolumn{3}{|l|}{ Number of ANC visits } \\
\hline Less than 4 times & 7 & 2.4 \\
\hline 4 times or more & 287 & 97.6 \\
\hline \multicolumn{3}{|l|}{ First ANC visit during: } \\
\hline First trimester (0-3 months) & 190 & 64.6 \\
\hline Second trimester (4-6 months) & 97 & 33 \\
\hline Third trimester $(7+$ months $)$ & 7 & 2.4 \\
\hline $\begin{array}{l}\text { Received at least three focused antenatal care } \\
\text { services* }\end{array}$ & 281 & 95.6 \\
\hline \multicolumn{3}{|l|}{ Went to different facility } \\
\hline By referral & 19 & 70.4 \\
\hline Without referral & 8 & 29.6 \\
\hline \multicolumn{3}{|c|}{$\begin{array}{l}\text { "Serious complications of pregnancy included Swollen feet, Ab- } \\
\text { dominal pain, Vaginal bleeding, backache, Convulsions, uncon- } \\
\text { sciousness *Focused antenatal care services selected: tetanus tox- } \\
\text { oid, intermittent preventive treatment for malaria, folate-iron sup- } \\
\text { plement, counseling on pregnancy complications. }\end{array}$} \\
\hline
\end{tabular}


Table 2 shows the care seeking behaviors reported by the women during their pregnancy. Almost all women (98\%) received antenatal care from a skilled provider. Among these, most (98\%) sought antenatal care from a skilled provider for at least four times during their last pregnancy, as recommended.

However, about $35 \%$ of women delayed antenatal care seeking until after the first trimester had elapsed. When asked to chronicle the places they had sought antenatal care, it was discovered that antenatal care had been obtained from multiple sources.

Although most women sought antenatal care from a biomedical health facility, this care was in addition to and often simultaneous with alternatives including tradition/herbal medicine, spiritual care, and selfmedication. Only $7 \%$ of women reported seeking care from other places as a result of a referral from their first place of care. Additionally, on average, only about $8 \%$ of women reported self-medication at any point along their care seeking pathway. About $45 \%$ of women utilized obtained antenatal care services from alternative care sources (spiritual, herbal, self-medication) in addition to biomedical care, during their last pregnancy.

Although most sought biomedical care, $14 \%$ of the women who sought any form of care did not go to a medical health facility as the first source of antenatal care. Instead, they utilized traditional/herbal care, spiritual/prayer support, or self-medication as their first source of antenatal care. Subsequently, however, most of these women $(80.0 \%)$ went to a hospital or health center for care.

\section{Box 1: A Case of Multiple Antenatal Care Shopping}

Yaa (pseudonym) is a 30 year old school teacher who participated in the survey. Yaa has secondary education. She has two children in addition to her last delivery. During her last pregnancy, she was registered with the national health insurance. Upon realizing that she was pregnant, she first visited a private health facility at Amasaman for antenatal care. Subsequently, she sought care from a traditional healer at Taifa near her home (altogether visited healer 9 times). While seeking this care, she also sought spiritual care from a spiritualist at a prayer camp (altogether visited spiritualist 9 times). Sometime during her pregnancy, she visited the private clinic at Amasaman again and was referred to a government health center at Pokuase where she sought care 5 times. Additionally, she went for antenatal clinics near her home for 4 times until she delivered at a government hospital.
On the other hand, among those who first went to either a hospital or health care facility, about a third, subsequently reported seeking alternative care from herbal, spiritual, and self-medication sources. This pattern of multiple shopping for antenatal care seeking behavior is illustrated in Box 1.

Among those who reported pregnancy-related complications, about $20 \%$ reported using home remedies while $16 \%$ did not report any form of care seeking for these symptoms. About $9 \%$ of those who reported pregnancy-related symptoms reported seeking care from a facility, other than the one they were regularly seeking antenatal care from. However, $26 \%$ of those who went to seek care elsewhere did not do so with a referral from their regular antenatal care provider. In a multivariate logistic regression model that controlled for household size, and gestational age, residence in the Taifa/Kwabenya sub district, history of abortion, and older age were identified as risk factors for multiprovider care seeking (Table 3).

Table 3 Factors associated with simultaneous antenatal care seeking from multiple providers

\begin{tabular}{|l|l|l|}
\hline Characteristics & $\begin{array}{l}\text { Odds ratio } \mathbf{9 5 \%} \text { Confidence Inter- } \\
\text { vals) }\end{array}$ \\
\hline & Non-adjusted & Adjusted \\
\hline Sub-districts & & \\
\hline Madina (reference) & 1 & 1 \\
\hline Taifa/Kwabenya & $2.41(1.48,3.92)$ & $2.13(1.28,3.55)$ \\
\hline Ever aborted a pregnancy & & \\
\hline No (reference) & 1 & 1 \\
\hline Yes & $1.89(1.06,3.38)$ & $2.08(1.11,3.91)$ \\
\hline Age & $0.92(0.88,0.97)$ & $0.92(0.87,0.97)$ \\
\hline Household wealth tertiles & & \\
\hline Lowest (reference) & 1 & 1 \\
\hline Middle & $1.25(0.71,2.19)$ & $0.69(0.37,1.31)$ \\
\hline Highest & $0.85(0.48,1.49)$ & $0.87(0.45,1.59)$ \\
\hline $\begin{array}{l}\text { Month of first antenatal } \\
\text { care }\end{array}$ & 1.06 & $0.99(0.84,1.19)$ \\
\hline Household size & & $0.93(0.78,1.09)$ \\
\hline
\end{tabular}

\section{DISCUSSION}

The current study was designed to describe pathways to care seeking during pregnancy among urbandwelling Ghanaian women. We found that almost all the women in the survey had received antenatal care from a skilled provider (either a nurse or medical doctor) in a licensed biomedical health facility. However, when we asked the same women to chronicle the places they sought antenatal care, they reported other sources of antenatal care that were not identified by the standard survey question (where did you seek antenatal care during your last pregnancy?).

The standard survey question thus failed to reveal the complicated nature of antenatal care seeking behavior among this group of urban-dwelling women ${ }^{6}$. 
The alternative questioning approach revealed that, most women indeed accessed skilled antenatal care from a biomedical health facility, and usually as the first source of care. However, they also sought care from alternative care providers.

Among this group of women, care seeking during pregnancy was often obtained from multiple providers. This multi-provider care-seeking behavior is, however, not unique among this group of urban women., ${ }^{9,10}$ Thus, a key finding of this study is that alternative care seeking during pregnancy is common among urbandwelling women in Accra. To the best of our knowledge, this is the first evidence describing the pattern of multiple antenatal care-seeking behaviors among urban-dwelling women in Ghana.

There are two key lessons to draw from this finding. Firstly, based on evidence from the qualitative enquiries (reported elsewhere) ${ }^{13}$ which demonstrated strong belief among women in the use of alternative and simultaneous antenatal care among most of the women suggests that, our estimate of alternative care seeking is likely to be less than reality. The evidence suggests further that it may be difficult to routinely obtain a true estimate of alternative care seeking using a recall survey tool, as was used in the current survey.

Secondly, considering the multiplicity of provider shopping among this urban-dwelling group of women, using an aggregate indicator of antenatal care such as the one used by the Demographic and Health Surveys (i.e., Percentage of fertile women receiving antenatal care from a skilled provider for the most recent birth) is useful but an insufficient description of women's antenatal care seeking. ${ }^{6}$

Our survey also demonstrated that women commonly shopped across different types of care providers during their pregnancy. Part of this antenatal multi-provider shopping represents a norm in Ghana where women often migrate to their hometown during pregnancy to benefit from psychosocial care and support during pregnancy. This relocation may then result in changing care providers. In our sample, relocation during pregnancy was observed among only a quarter of the women.

The respondents care seeking may partly be driven by a combination of different beliefs and perceptions including the belief that there is complementary and synergistic abilities of different remedies, and that herbal medicine is superior to biomedical remedies for some ailments, and also the belief that some aspects of maternity care is best dealt with outside biomedical care. $^{14-16}$
These firmly held beliefs attract pregnant women to utilize alternative care services. The study thus suggests the need for exploring the role of behavior change communication that aims to dispel potentially harmful beliefs while recognizing and integrating alternative care providers into the continuum of care for pregnant women. If women will seek out alternative care providers, perhaps, these providers can be linked up to the biomedical health system as referral points.

In addition, training alternative care providers to recognize when to make referrals is an unexplored option that should be tested as a potential strategy for limiting failure to seek care or delayed care seeking during pregnancy. Further studies are needed to test the feasibility of implementing such interventions.

\section{CONCLUSIONS}

The current study found that most women in the Ga East district utilized biomedical health facilities, and were attended by skilled personnel during their pregnancy. Nevertheless, almost half of the women simultaneously utilized alternative care options. Living in a community with limited access to biomedical care as well as a history of abortion is associated with seeking antenatal care from multiple sources. This finding calls for interventions that recognize a role for integrating alternative care providers with biomedical health care system. In addition, there is much room for behavior change targeted at both the community and the health system.

\section{REFERENCES}

1. World Health Organization (WHO), United Nations Children's Fund (UNICEF), United Nations Population Fund (UNFPA), The World Bank (WB). Trends in Maternal Mortality: 1990 to 2010. Geneva: World Health Organization; 2012:33.

2. Ghana Statistical Service (GSS), Ghana Health Services (GHS), Macro Inc. Ghana Maternal Health Survey. Accra: Ghana Statistical Service; 2007:32-33.

3. Ministry of Health, Government of Ghana, United Nations Country Team. MDG Acceleration Framework And Country Action Plan: Maternal Health. Accra: Ministry of Health; 2011:23-25.

4. Ronsmans C, Graham W. Maternal mortality: Who, when, where, and why. The Lancet. 2006;368:1189-1200.

5. Thaddeus S, Maine D. Too far to walk: Maternal mortality in context. Social Science \& Medicine. 1994;38(8):1091-1110.

6. Ghana Statistical Service G, Ghana Health Services G, ICF Macro. Ghana Demographic and 
Health Survey 2008. Accra: GSS, GHS, ICF Macro; 2009:148.

7. Campbell M, Abu Sham Z. Sudan: situational analysis of maternal health in Bara District, North Kordofan. World Health Stat Q. 1995;48(1):60-66.

8. Martey JO, Djan JO, Twum S, Browne EN, Opoku SA. Maternal mortality and related factors in Ejisu District, Ghana. East Afr Med J. Oct 1994;71(10):656-660.

9. Family Care International. Care-Seeking During Pregnancy, Delivery, and the Postpartum Period: A Study in Homabay and Migori Districts, Kenya. Nairobi: Family Care International; 2003:11-13.

10. Moran AC, Winch PJ, Sultana N KN, et al. Patterns of maternal care seeking behaviours in rural Bangladesh. Trop Med Int Health. 2007;12(7):823-832.

11. Ampofo DA, Nicholas DD, Amonoo-Acquah MB, Ofosu-Amaah S, AK. N. The training of traditional birth attendants in Ghana: experience of the Danfa Rural Health Project. Trop Geogr Med. 1977;29(2):197-203.

12. Aryeetey R, Kotoh AM, Hindin MJ. Knowledge, perceptions and ever use of modern contraception among women in the Ga East District, Ghana. Afr $j$ Reprod Health. Dec 2010;14(4 Spec no.):26-31.

13. Dako-Gyeke P, Aikins M, Aryeetey R, McCough L, Adongo PB. The influence of socio-cultural interpretations of pregnancy threats on healthseeking behavior among pregnant women in urban Accra, Ghana. BMC pregnancy and childbirth. Nov 19 2013;13(1):211.

14. Syed U, Khadka N, Khan A, Wall S. Care-seeking practices in South Asia: using formative research to design program interventions to save newborn lives. J Perinatol. Dec 2008;28 Suppl 2:S9-13.

15. Simkhada B, Teijlingen ER, Porter M, Simkhada P. Factors affecting the utilization of antenatal care in developing countries: systematic review of the literature. J Adv Nurs. Feb 2008;61(3):244-260.

16. Ndyomugyenyi R, Neema S, Magnussen P. The use of formal and informal services for antenatal care and malaria treatment in rural Uganda. Health Policy Plan. Mar 1998;13(1):94-102. * 